\title{
Study Day of Microscopic Findings
}

National Cancer Institute

\section{Source}

National Cancer Institute. Study Day of Microscopic Findings. NCI Thesaurus. Code C117600.

The day that a microscopic findings assessment is performed. 